\title{
Public attitudes toward animals and the influential factors in contemporary China
}

Citation for published version (APA):

Su, B., \& Martens, P. (2017). Public attitudes toward animals and the influential factors in contemporary China. Animal Welfare, 26(2), 239-247. https://doi.org/10.7120/09627286.26.2.239

Document status and date:

Published: 01/05/2017

DOI:

10.7120/09627286.26.2.239

Document Version:

Publisher's PDF, also known as Version of record

Document license:

Taverne

Please check the document version of this publication:

- A submitted manuscript is the version of the article upon submission and before peer-review. There can be important differences between the submitted version and the official published version of record.

People interested in the research are advised to contact the author for the final version of the publication, or visit the DOI to the publisher's website.

- The final author version and the galley proof are versions of the publication after peer review.

- The final published version features the final layout of the paper including the volume, issue and page numbers.

Link to publication

\footnotetext{
General rights rights.

- You may freely distribute the URL identifying the publication in the public portal. please follow below link for the End User Agreement:

www.umlib.nl/taverne-license

Take down policy

If you believe that this document breaches copyright please contact us at:

repository@maastrichtuniversity.nl

providing details and we will investigate your claim.
}

Copyright and moral rights for the publications made accessible in the public portal are retained by the authors and/or other copyright owners and it is a condition of accessing publications that users recognise and abide by the legal requirements associated with these

- Users may download and print one copy of any publication from the public portal for the purpose of private study or research.

- You may not further distribute the material or use it for any profit-making activity or commercial gain

If the publication is distributed under the terms of Article $25 \mathrm{fa}$ of the Dutch Copyright Act, indicated by the "Taverne" license above, 
www.ufaw.org.uk

\title{
Public attitudes toward animals and the influential factors in contemporary China
}

\author{
B Su* and P Martens
}

International Centre for Integrated Assessment and Sustainable Development (ICIS), Maastricht University, PO Box 616, 6200 MD Maastricht, The Netherlands

* Contact for correspondence and requests for reprints: Bingtao.Su@maastrichtuniversity.nl

\begin{abstract}
The relationship between public attitudes toward animals and human demographics has been well documented during the last few decades, but the influence of human ethical ideologies on public attitudes toward animals and animal welfare has been rarely investigated, especially in developing countries, such as China. The present study introduced two scales (Animal Issue Scale [AIS] and Animal Attitude Scale [AAS]) to investigate the Chinese people's attitudes toward animals and the manner in which their outlook related to ethical ideologies (idealism and relativism), which classified people into four ethical positions: situationists, subjectivists, absolutists and exceptionists. Moreover, it also showed how ethical ideologies and their interaction with human demographics influence respondents' attitudes toward animals. The results of an online questionnaire $(n=504)$ distributed throughout China suggest that compared with middle-aged and old respondents, the young demonstrated significantly more positive attitudes toward animals. Absolutists showed the most positive attitudes toward animals, while subjectivists showed the least. People's attitudes toward animals were positively affected by idealism, which confirms previous findings in developed countries. However, people's attitudes toward animals were negatively affected by relativism, which is inconsistent with findings in developed countries, showing that ethical relativism failed to influence attitudes toward animals. Our results indicate that the same mechanisms underlying the effect of ethical idealism on attitudes toward animals might work in different countries to increase awareness on animal welfare. However, the manner in which ethical relativism influences attitudes toward animals may differ between developed and developing countries.
\end{abstract}

Keywords: animal welfare, attitudes, China, demographics, ethical idealism, ethical relativism

\section{Introduction}

Public attitudes toward animals and the influential factors are of central concern within the fields of human-animal relationships and animal welfare (Serpell 2004; Spooner et al 2012). In recent years, a growing body of survey-based research has revealed that most people showed positive attitudes to animals as animals had many measurable benefits, both to humans and to society, such as enhancing physical and psychological wellbeing, reducing loneliness and depression, improving animal diversity and promoting sustainable nature and society development (Goldmeier 1986; Sharkin \& Knox 2003; Wrobel \& Dye 2003; Blazina et al 2011). From another perspective, the manner in which public attitudes toward animals are presented - a factor influenced by human culture and knowledge - can contribute to a healthy dietary and living environment for animals leading, ultimately, to an optimum animal welfare system. Therefore, it is clear that a better understanding of public attitudes toward animals, as well as the effects of influential factors on such attitudes, are fundamentally important to both animals and humans.

There are a variety of attitudes toward animals around the world and multitudinous reasons exist behind each. Key drivers of these attitudes may include the geographic region, economy, human demographic, purpose of animal usage, human culture and religion (Driscoll 1992; Phillips et al 2012). For instance, European students have more concern for animal welfare than Asian students, whilst compared with northern European students, students from communist Asian and European countries have more concern about killing animals (Phillips et al 2012). Additionally, children and adults often show different views toward animals. Humanistic, moralistic, naturalistic and ecologistic are the four prevaling attitudes among 12-14 year old children (Eagles \& Muffitt 1990), while adults often show confused attitudes toward animals. Individuals may differ in their attitudes to how people use animals. For example, using animals for luxury garments is the most unacceptable behaviour, and the use of animals for educational purposes the most acceptable (Driscoll 1992), while attitudes toward farm animals should depend on the situation and the measurement model (Hansson \& Lagerkvist 2014). People tend to be more favourable towards popular as opposed to unpopular animals (Prokop \& Tunnicliffe 2010). Companion animal owners often show better knowledge of and more positive attitudes toward both popular and 


\section{Figure I}

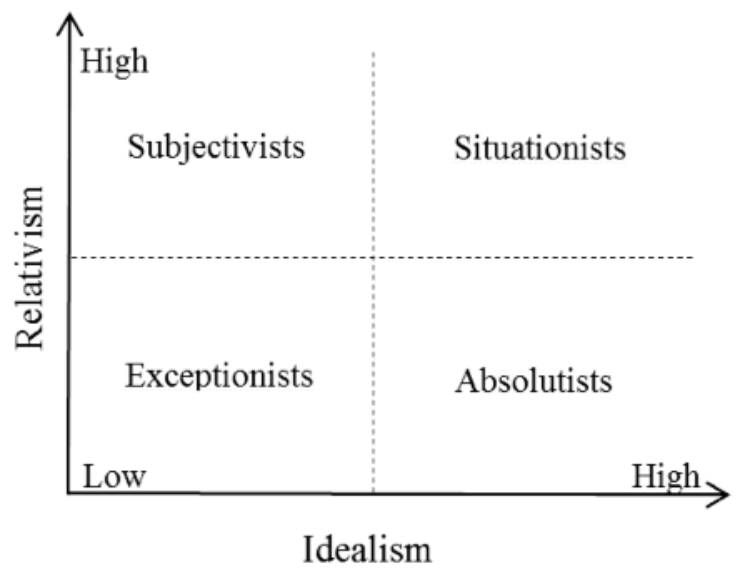

Ethical positions according to idealism and relativism.

unpopular companion animals than non-owners (Dalla Costa et al 2014). Culture can also influence people's attitudes toward animals. In India and Nepal, primates are viewed as sacred; while in China and Japan, primates are mythical creatures (Lee \& Priston 2005). All these studies elucidate the possible factors influencing public attitudes toward animals and most also made mention of the role of human demographics, such as age, gender, education and occupation (Kellert \& Berry 1980, 1987; Kellert 1985a,b; Herzog Jr et al 1991; Signal \& Taylor 2006).

However, only a small number of studies have sought to analyse the link between ethical ideologies and attitudes toward animals (Galvin \& Herzog 1992; Wuensch \& Poteat 1998). Forsyth's (1980) Ethics Position Questionnaire (EPQ) was often used to measure people's ethical ideologies. The EPQ was divided into two sub-scales: ethical idealism and ethical relativism. Individuals scoring high on the idealism sub-scale think that ethical behaviour will always lead to positive consequences, while individuals who score high on the relativism sub-scale reject the universal moral principles and believe that moral decisions should be based on personal or situational analysis (Forsyth 1980; Galvin \& Herzog 1992). Forsyth (1980) also classified people into four possible ethical positions: situationists (high idealism and high relativism), subjectivists (low idealism and high relativism), absolutists (high idealism and low relativism) and exceptionists (low idealism and low relativism) (Figure 1). He proposed that absolutists rated animal experiments as more unethical than did individuals in any of the other ethical categories (Forsyth \& Pope 1984).

According to the EPQ, Galvin and Herzog (1992) found a significant correlation between people's ethical ideologies and their attitudes toward animals. They suggested that positive attitudes to animals and their welfare were positively linked with ethical idealism. This study was conducted in developed countries where people already had a high awareness of animal welfare. We question whether the links between ethical ideologies and attitudes to animals could be low in a country where the awareness of animal welfare is poor, since a low link between ideologies and attitudes to animals could explain the poor awareness in such countries. China was selected as being representative of such a country since an awareness of animal welfare is considered low. The present study aims to capture the correlations between ethical ideologies and attitudes towards animals in contemporary China and check whether people's attitudes to animals are linked to demographic factors in China as in other countries.

\section{Materials and methods}

\section{Questionnaire}

Research into public ethical ideologies and attitudes toward animals in contemporary China was conducted in November 2015. During this period, an online survey was carried out by means of simple random sampling (Tillé 2006; Kirk 2011) of Chinese people. One limitation of this study was that only $6.5 \%$ of surveys originated from rural areas probably due to limited internet access in such places, people's reluctance to respond and their relatively lower level of education. Consequently, the sample population does not represent the general Chinese population.

The questionnaire consisted of four sections (see the supplementary material to papers published in Animal Welfare on the UFAW website: http://www.ufaw.org.uk/t-ufawjournal/supplementary-material). Demographic details and a variety of other basic facts were requested in the first section, including age, gender, highest level of education, animal protection/nature conservation/human health organisation participation, composition of household, place of residence, the sort of house, the importance of religion/spirituality, the main source of inspiration, household income, pet ownership, pet species, meat eating and zoo (aquarium) visiting frequency.

In the second section, the EPQ was used to measure the differences in personal moral philosophy (Forsyth 1980; Galvin \& Herzog 1992) in China. The EPQ is a 20-item Likert scale, which was divided into two sub-scales, one was designed to measure ethical idealism and the other was for ethical relativism. Respondents were asked to respond to statements using the nine-point EPQ ranging from 1 (completely disagree) to 9 (completely agree). In addition, two cut-off values of 7.26 (the mean score of idealism subscale) and 6.07 (the mean score of relativism sub-scale) were introduced to classify participants as high or low in idealism and relativism. This procedure produced four possible ethics positions: situationists, subjectivists, absolutists and exceptionists (Forsyth 1980; Galvin \& Herzog 1992). Examples of questions include: 'One should never psychologically or physically harm another person'; 'What is ethical varies from one situation and society to another'; 'Different types of morality cannot be compared as to "rightness".

In the third section, Animal Issue Scale (AIS) (Meng 2009), which includes eight animal issues (use of animals, animal integrity [destruction], killing animals, [deprive] animal welfare, experimentation on animals, changes in animals' genotypes, animals and the environment [harm animals for 
environment], and societal attitudes toward animals [harm animals for social issues]), was introduced to respondents in order to assess their attitudes toward animals. There are 43 questions in AIS and each question is rated on a five-point scale ranging from 1 (extremely acceptable) to 5 (extremely unacceptable). A high score on a question indicates a low level of acceptability of the issues (Phillips et al 2012). Typical items include: 'Using animals for work'; 'Killing young animals that are dependent on their parents'; 'Controlling wildlife populations by killing'.

In the fourth section, the Animal Attitudes Scale (AAS) (Herzog Jr et al 1991) was used to further measure public attitudes toward animals. Due to its scientific content and concise design, the AAS was chosen for this research. The current AAS, a 20-item Likert-scale, was simplified from a 29-item scale by using factor analysis (Herzog Jr et al 1991). Most items are scored from 1 (strongly agree) to 5 (strongly disagree), while items of 1, 3, 4, 7, 10, 11, 17, 19 and 20 are reverse-scored from 1 (strongly disagree) to 5 (strongly agree). The AAS score is the sum of the 20-item scores. A high score reflects a high awareness of animal protection. Examples of questions include: '1) It is morally wrong to hunt wild animals just for sport'; '5) There is nothing morally wrong with hunting wild animals for food'; '20) The use of animals in rodeos and circuses is cruel'.

\section{Statistical analysis}

Public ethical ideologies and attitudes toward animals in contemporary China were analysed with IBM SPSS 21 Statistical software. The data used in this study were either normally distributed or translated into normal distribution, and the Levene test showed homogeneity of the variances. A multivariate analysis (MANOVA, with Fisher's LSD correction) was performed to determine respondents' ethical ideologies and demographics that may affect their attitudes toward animals. Following an initial analysis, the residual data distribution was examined and, where necessary, transformed to approximate a normal distribution (Izmirli \& Phillips 2011; Phillips et al 2012). The model for data responses included ethical ideologies, gender, age, highest level of education, animal protection/nature conservation/human health organisation participation, composition of household, place of residence, the sort of house, the main source of religion/spirituality, pet ownership and species, household income, meat eating and zoo (aquarium) visiting frequency. Only ethical idealism, ethical relativism, gender and age were considered in this paper because idealism and relativism were the two targeted variables in the modelling here. Gender and age were utilised to gauge the influence of basic human demographics and their interaction with ethical ideologies on public attitudes toward animals. Notice that the Bonferroni correction was also employed in the tests to control for type I errors due to repeated testing (Cabin \& Mitchell 2000; Martens et al 2016). In order to find out which variables determined public attitudes toward animals, step-wise linear regression was implemented to relate response in AIS and AAS to participants' demographics and their basic information (eg animal protection/nature conservation/human health organisation participation, pet ownership and household income), following the model described above and using an alpha value of 0.05 for variables to enter the model. All the non-explanatory variables were removed from the results (McDonald 2009).

\section{Results}

\section{Response rates}

A total of 504 responses were obtained from 527 people among a panel which included 5,630 people throughout China who provided their e-mail addresses and received our invitation email with a unique hyperlink to our questionnaire. The mean $( \pm$ SD) age of all respondents $(41.7 \%$ female and $58.3 \%$ male) was $39.97( \pm 13.31)$ years. The majority of completed surveys $(93.5 \%)$ were returned from urban areas, while only $6.5 \%$ were from rural areas. Additionally, several other variables were studied in this research, such as pet ownership (33.3\% of respondents owned a dog, $17.1 \%$ owned a cat, $13.5 \%$ owned fish, $5.4 \%$ owned birds, $4.2 \%$ owned reptiles, $0.8 \%$ owned rodents, $4.2 \%$ owned poultry and $0.2 \%$ owned ponies and horses), animal protection/nature conservation/human health organisation participation $(22.6 \%$ of respondents had belonged or donated to an organisation involved in improving the welfare of animals; $48.8 \%$ were involved in conservation of the natural environment; $32.9 \%$ were concerned with improving human rights or health) and household income $(9.4 \%$ respondents' household incomes were on the level of the minimum wage or below the minimum wage in China, $34.5 \%$ respondents' household incomes matched the national average in China, $41.3 \%$ of respondents' household incomes were twice that of the national average in China, $13.9 \%$ of respondents' household incomes were more than twice the national average in China, and $1.0 \%$ gave no answer).

\section{The EPQ}

In this research, respondents scored slightly higher on the idealism scale (7.26 [ \pm 1.21$])$ than did Forsyth's (1980) respondents $(6.35[ \pm 1.17])$, and slightly lower $(6.07[ \pm 1.33])$ than Forsyth's $(6.18[ \pm 1.13])$ on the relativism scale. Compared to young respondents, middle-aged and old respondents had a higher score on the idealism scale; while the young had a higher score on the relativism scale than the middle-aged and the old. However, the differences of ethics levels of both idealism and relativism scales between male and female respondents were not significant ( $t=0.49, P=0.63 ; t=0.49, P=0.63$ ) (Figure 2). Of the respondents in the current research, $32.6 \%$ were situationists, followed by exceptionists $(26.0 \%)$ and absolutists (23.6\%), while only $17.8 \%$ of respondents were subjectivists.

\section{The AIS and AAS}

The participants in this study showed a mean $( \pm \mathrm{SD})$ score of $135.69( \pm 18.10)$ out of 215 on the AIS and $63.07( \pm 7.83)$ out of 100 on the AAS. The AIS scores of absolutists, situationists, subjectivists and exceptionists were $140.57( \pm 16.99), 136.29( \pm 20.39), 130.89( \pm 18.00)$ and $134.74( \pm 15.67)$, respectively, while the AAS scores for the four ethical positions were $65.35( \pm 9.83), 63.53( \pm 7.70)$, $61.19( \pm 6.56)$ and $62.19( \pm 6.50)$. 
Figure 2

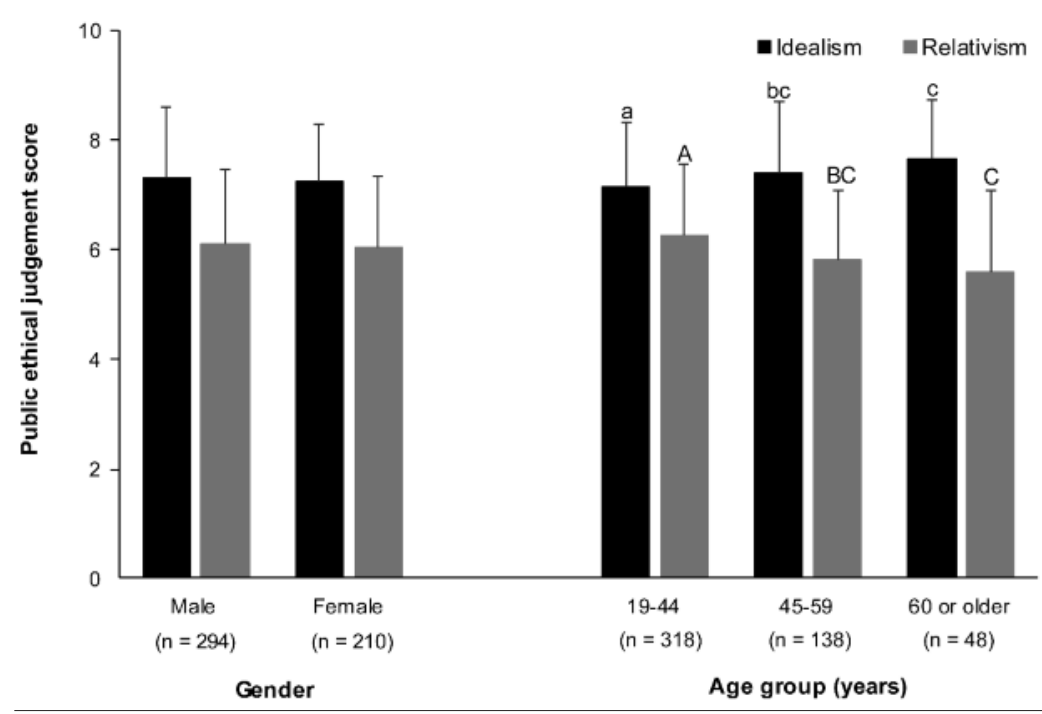

The scores for Chinese public ethical judgement. a,b, indicate significant difference amongst three age groups of people in the idealism scale; and $A, B, C$ indicate significant difference amongst three age groups of people in the relativism scale.

The influence of ethical ideologies and demographics on public attitudes toward animals

\section{Ethical ideologies}

Respondents' ethical idealism and relativism significantly affected their attitudes toward animals (according to their AIS and AAS scores) (see Table 1[a], [b] in the supplementary material to papers published in Animal Welfare on the UFAW website: http://www.ufaw.org.uk/t-ufawjournal/supplementary-material). When having a higher idealism score, respondents showed more positive attitudes toward animals, and this resulted in more negative attitudes toward 'killing animals', 'deprive animal welfare', 'harm animals for environment' and 'harm animals for social issues'. When having a higher level of ethical relativism, respondents showed less positive attitudes toward animals, resulting in a higher acceptability of 'use of animals', 'animal integrity destruction', 'killing animals', 'deprive animal welfare', 'changes in animals' genotypes', 'harm animals for environment' and 'harm animals for social issues' (Table 1[a], [b]; http://www.ufaw.org.uk/t-ufawjournal/supplementary-material). Absolutists showed the most positive attitudes toward animals, while subjectivists showed the least positive attitudes toward animals. However, there was no interaction between ethical idealism and relativism on attitudes toward animals, although we found that the correlations between attitudes toward animals (measured by AIS and AAS, respectively) and ethical ideologies were stronger for ethical idealism $(r=0.153$, $r=0.151)$ than for ethical relativism $(r=-0.120$, $r=-0.101)$ (both $P<0.001)$ (data not presented).

\section{Human demographics}

Young respondents had more positive attitudes toward animals than the middle-aged and the old. This difference can also be reflected by young respondents' lower acceptability of 'use of animals', 'animal integrity destruction', 'killing animals', 'experimentation on animals', 'changes in animals' genotypes' and 'harm animals for environment' (Table 1[a], [b]; http://www.ufaw.org.uk/t-ufawjournal/supplementary-material). Gender as an independent variable did not influence respondents' attitudes toward animals; although a gender by age interaction effect was found whereby only young female respondents showed significant negative attitudes toward 'changes in animals' genotypes' (Table 1[a], [b]; http://www.ufaw.org.uk/t-ufawjournal/supplementary-material).

\section{The interaction of ethical ideologies and human demographics}

The interaction of idealism and gender did not influence respondents' attitudes toward animals. However, the effect of ethical idealism on decreasing the acceptability of 'harm animals for social issues' was stronger in the absence of male respondents (ethical idealism $\times$ gender). Vice versa, the accelerating effect of female respondents on the negative attitudes toward 'harm animals for social issues' was stronger for absolutists and situationists (a higher level of ethical idealism) than exceptionists and subjectivists (a lower level of ethical idealism) (Table 1[a], [b]; [see http://www.ufaw.org.uk/t-ufaw-journal/supplementarymaterial]). Additionally, the accelerating effect of female respondents on attitudes toward 'killing animals' was more negative in exceptionists and absolutists (a lower level of ethical relativism) than in situationists and subjectivists (a higher level of ethical relativism) (ethical relativism $\times$ gender). A decreasing trend of ethical relativism with the decreased age, increased respondents' positive attitudes toward animals (only according to their AIS score) and negative attitudes toward 'animal integrity destruction' and 'killing animals' (ethical relativism $\times$ age) (Table 1[a], [b]; http://www.ufaw.org.uk/t-ufawjournal/supplementary-material).

We found age by ethical idealism by ethical relativism interaction affected respondents' attitudes toward specific animal 
Table 2 Important variables to the score of Animal Issue Scale (AIS) in China.

Y: The attitudes toward animals $(\mathrm{df}=104)$

Unstandardised coefficients t-value Probability

B-value Standard Error

\begin{tabular}{|c|c|c|c|c|}
\hline Constant & 135.30 & 8.99 & 15.06 & $P<0.01$ \\
\hline $\begin{array}{l}X_{1} \text { : What is your gross household income per month? Average or below the } \\
\text { average income in China (I) - twice or more than twice the average income } \\
\text { in China (2) }\end{array}$ & -11.40 & 4.32 & -2.64 & $P=0.01$ \\
\hline $\mathrm{X}_{2}:$ What pets do you have? Dogs: No $(0)$ - Yes $(I)$ & 24.95 & 5.14 & 4.86 & $P<0.01$ \\
\hline $\mathrm{X}_{3}$ : What pets do you have? Rodents: No (0) - Yes (I) & 26.08 & 11.36 & 2.30 & $P=0.02$ \\
\hline
\end{tabular}

Table 3 Important variables to the score of Animal Attitudes Scale (AAS) in China.

Y: The attitudes toward animals $(\mathrm{df}=104)$

Unstandardised coefficients t-value Probability

B-value Standard Error

\begin{tabular}{|c|c|c|c|c|}
\hline Constant & 66.73 & 3.84 & 17.36 & $P<0.01$ \\
\hline $\begin{array}{l}X_{1} \text { : Do you belong or donate to an organisation or charity involved in or con- } \\
\text { cerned with improving the welfare of animals? Yes (I) - No (2) }\end{array}$ & -4.87 & 1.61 & -3.02 & $P<0.01$ \\
\hline $\begin{array}{l}X_{2} \text { : Do you belong to or donate to an organisation or charity involved in or } \\
\text { concerned with improving human rights or health? } \operatorname{Yes}(I) \text { - No (2) }\end{array}$ & 5.58 & 1.62 & 3.45 & $P<0.01$ \\
\hline $\begin{array}{l}X_{3} \text { : What is your gross household income per month? Average or below the } \\
\text { average income in China (I) - twice or more than twice the average income } \\
\text { in China (2) }\end{array}$ & -4.22 & 1.58 & -2.67 & $P<0.01$ \\
\hline $\mathrm{X}_{4}:$ What pet(s) do you have? Dogs: No (0) - Yes (I) & 5.68 & 1.90 & 3.00 & $P<0.01$ \\
\hline
\end{tabular}

issues. Young absolutists showed the most negative attitudes toward 'deprive animal welfare', while old subjectivists showed the least negative attitudes toward 'deprive animal welfare' (age $\times$ ethical idealism $\times$ ethical relativism) (Table 1[a], [b]; http://www.ufaw.org.uk/t-ufawjournal/supplementary-material). The interaction of age, gender and ethical relativism also influenced respondents' attitudes toward animals (according to their AIS and AAS scores). Female absolutists and exceptionists showed more negative attitudes toward 'killing animals' and 'experimentation on animals', although their age was younger they demonstrated more positive attitudes toward animals (age $\times$ gender $\times$ ethical relativism) (Table 1[a], [b]; http://www.ufaw.org.uk/t-ufawjournal/supplementary-material).

\section{Place of residence}

We also investigated whether a relationship exists between respondents' attitudes toward animals and their living places because the gap between urban and rural areas is one of the most significant characteristics of contemporary China. However, we found neither living areas nor its interaction with ethical ideologies and human demographics influenced respondents' attitudes toward animals (according to their AIS and AAS scores) (data not presented).

\section{Other important determinants of the AIS and AAS}

A number of participants' demographic variables were identified that influenced their attitudes toward animals (according to their AIS score). Results showed that the respondents whose household income was twice or greater than the national average in China averaged 11.40 points below those whose household income matched or was below the average. Our results also showed that those reporting that they owned a pet had higher scores than those who did not, and these differences were based on the different animal species: 24.95 points by owning a dog and 26.08 by owning a rodent (Table 2 ).

In order to further explore the influential factors behind respondents' attitudes toward animals, we considered all the possible demographic variables that might influence respondents' AAS score (used to measure their attitudes toward animals). Results showed that respondents who owned a pet dog had an AAS score 5.68 points higher than those that did not. The respondents who belonged or donated to an organisation involved in improving animal welfare had an average AAS score 4.87 points greater than those who did not, whilst those individuals belonging or donating to organisations concerned with improving human rights or health showed an average AAS score 5.58 points lower than those not fitting this profile. Household income was another factor that influenced public attitudes toward animals. Participants whose household income was twice or greater than the national average had a score 4.22 points below individuals whose household income was equal to or below the national average (Table 3 ). 


\section{Discussion}

The aim of this study was to investigate how ethical ideologies and their interaction with human demographics influence public attitudes toward animals in China. In contrast with previous research (Galvin \& Herzog 1992), reporting that the correlation between ethical ideologies and attitudes toward animals was significant on idealism but not on relativism, our results indicate a largely independent effect of both ethical idealism and relativism on public attitudes toward animals. Specifically, respondents who scored higher on ethical idealism and scored lower on ethical relativism generally had higher scores on both animal issue scale (AIS) and animal attitude scale (AAS), independent of gender and age. This finding demonstrates that the belief of ethical behaviour will always lead to good results and the existence of universal moral principles can improve respondents' positive attitudes toward animals. Overall, the majority of Chinese people showed positive attitudes toward animals. Young respondents had higher AIS and AAS scores than middle-aged and old respondents and the older the person, the lower the AIS and AAS scores.

\section{Ethical ideologies and attitudes toward animals}

We confirmed that people's moral idealism significantly influenced their attitudes toward animals (McPhedran 2009; Bègue \& Laine 2016). The more those individuals (situationists and absolutists) considered their ethical behaviour would always lead to desirable consequences, the more they appreciated animals. Perhaps this association is most likely due to the idealist's reluctance to overlook animal suffering. For an idealist, the existence of any animal suffering renders the activities immoral, regardless of the benefits to be derived from activities (Wuensch \& Poteat 1998). Another possible explanation is that ethical idealism is related to empathy, which would be helpful in increasing people's concern for other creatures, although the direct support for this hypothesis is not available (Galvin \& Herzog 1992).

In contrast to a previous investigation reporting no significant correlation between ethical relativism and attitudes toward animals in the United States (Galvin \& Herzog 1992), our research indicates significant effects of ethical relativism on the attitude of the Chinese public to animals. This could be due to relativism featuring more in contemporary intellectual scenes (Sankey 2015). Therefore, the implications of ethical relativism become wider, even playing a role in influencing public attitudes toward animals, although we found respondents' attitudes toward animals were based more on their ethical idealism than relativism. Chinese people's lower awareness of animal welfare may also account for this difference. Many Chinese people can accept animal (eg rodents) suffering in research experiments when they consider the specific benefits that experiments bring. Such people feel no universal ethical principles exist in the world, which directly results in their tolerant attitude to animal use. These attitudes may also derive from the old Confucianism that states animals could be sacrificed for humans in order to pray for good harvest (Blakeley 2003).
Additionally, our results also reveal that a high level of ethical relativism could lead to relatively negative attitudes toward animals, suggesting that situationists and subjectivists generally had a low awareness of animal welfare. Those individuals reject the possibility of relying on universal moral principles. Hence, they are more likely to forgive certain types of ethical straying (animal suffering in medical experiments) according to their own moral principles (Sivadas et al 2003). For instance, individuals would regard animal experiments as acceptable since the use of animals in medical research can improve our understanding and our estimation of the risk to human populations (Knight et al 2009).

Looking more closely at ethical ideologies, subjectivists tended to show less favourable attitudes toward animals than any of the other categories, while absolutists found them more favourable than did individuals from any other ethical category. Probably the combination of the belief that ethical behaviour will always lead to positive consequences, and the belief that moral decisions should be based upon universal moral principles, promotes the positive attitudes of absolutists toward animals and animal welfare. Therefore, they cannot accept any unnatural behaviour of animals. Subjectivists contrast considerably with absolutists as regards their belief that the best activities do not lead to the best results. They tend to assess situations according to multi-principles and might be more open to different situations. Therefore, they showed a more tolerant attitude toward animal use, such as animal experimentation. Another possible explanation is that absolutists envision themselves as standing on the moral high ground, while subjectivists might accept anything that they regard as reasonable (Banas \& Parks 2002). Therefore, it is plausible that absolutists showed an absolutely positive attitude toward animals, while greater tolerance of animal suffering (eg animal experiments) was associated with subjectivists.

\section{Human demographics and attitudes toward animals}

In most surveys on attitudes toward animals, gender is often found to be a correlated factor (Herzog Jr et al 1991; Prokop \& Tunnicliffe 2010; Binngießer et al 2013). However, male and female respondents did not show any significant differences regarding their attitudes to animals, which is in contrast to a previous report that showed women to be more likely to have a positive attitude toward animals than men in the United States (Herzog Jr et al 1991). This finding might be due to the fact that women are regarded as being more concerned with animal welfare than men (Wuensch \& Poteat 1998). A further reason may lie in personality differences whereby men are less likely to have sympathetic reactions to animals than women, which directly result in their lower awareness of animal welfare. These differences are probably derived from men's lower levels of belief in the mental abilities of animals compared to women (Knight et al 2003). However, our results may arguably relate more closely to people's increasingly good morality and high concern for animal welfare, regardless of male or female respondents. Additionally, Chinese women and men's deep- 
rooted concept that animals should be respected as an essential part of society may also contribute to their similar attitudes toward animals (Blakeley 2003). It is therefore not surprising that there are no gender differences among Chinese respondents.

Respondents' attitudes toward animals became significantly less positive with an increase in age and the older the person, the less the positive the attitude. This finding partly parallels a previous work by Signal and Taylor (2006) who demonstrated a minimal negative correlation between age and attitudes toward animals in Australia, although this correlation was not significant. Several explanations may account for this result. First, older respondents are more likely to emphasise the practical value of animals than younger respondents (Ormandy \& Schuppli 2014). Their attitudes toward animals are based more on their thinking and reasoning than emotions and feelings of right and wrong. Therefore, utilitarian intentions may exist among older people because they think animals can be sacrificed for medical achievement and people's progress (Kellert \& Berry 1980). Second, animal welfare is a new phenomenon in China, so younger generations are more aware of it and show more positive attitudes toward animals (Littlefair 2006). Third, younger people in China have better education opportunities and more knowledge related to animal welfare than older people (Davey 2006).

In addition, due to the imbalanced sample (only $6.5 \%$ of the respondents were from rural areas), we were not able to demonstrate the radically different attitudes toward animals between urban and rural areas. Given the relatively limited number of respondents from rural areas in this study, this finding needs to be viewed with caution. In fact, the gap between rural and urban areas is one of the most crucial characteristics in contemporary China. Hence, further studies are needed to better address this topic.

\section{The interaction of ethical ideologies and human demographics on attitudes toward animals}

In this research, we found some interaction effects of ethical ideologies and gender on respondents' attitudes toward animals. These findings imply that gender plays a role in influencing respondents' attitudes to specific animal issues when it interacts with idealism or relativism, although we did not find any impact of gender itself on attitudes to animals. This might be explained by the relationship between gender and ethical ideology: men are more inclined than women to base their judgements on justice (relativism) rather than emotions (idealism), and vice versa (Galvin \& Herzog 1992). Additionally, the ethical relativism by age interaction effect on respondents' attitudes toward animals was significant only in terms of their AIS score, indicating that AIS, which include 43 items, might be more comprehensive in measuring public attitudes toward animals than AAS, which includes 20 items. This result also implies that absolutists and exceptionists' positive attitudes to animals decreased with age; the older the absolutists and exceptionists, the less the positive attitudes to animals.
The interaction of gender and age only affected respondents' attitudes toward the section of 'changes in animals' genotypes'. However, our results established a clear link between respondents' overall attitudes toward animals and the interaction of gender, age and ethical relativism, providing additional evidence of the validity of ethical relativism. Although we found no dramatic different interactions between idealism and relativism, it appears that the interactions of idealism, relativism and age on respondents' attitudes toward 'deprive animal welfare' show pronounced differences, indicating that young absolutists are inclined to show the most negative attitudes toward 'deprive animal welfare'. This might simply be the result of the fact that younger absolutists might be more reluctant to engage in immoral activities (eg animal experiments and animal suffering) when moral principles are made (Forsyth 1992).

\section{The influence of pet ownership and organisation participation on attitudes toward animals}

A further aim of this study was to figure out which variables determined public attitudes toward animals in China. We confirmed what many previous studies have already shown: companion animal owners were more likely to show intensive relationships with animals than non-owners (Paul \& Serpell 1993; Fidler et al 1996; Walker et al 2014). These results may be explained by the fact that companion animal owners have more opportunities to interact with animals than non-owners. Furthermore, findings in this research also reveal that animal protection organisation participation increased the positive attitudes toward animals, while human health organisation participation decreased the positive attitudes toward animals. The former finding might stem from participants' relatively frequent interactions with animals and nature in animal protection organisation. However, the latter might be due to their working ethos promoting the notion of using animals in experiments to promote medical development and improve human health.

\section{Limitations of this study}

Although the present study did achieve a degree of success by measuring Chinese people's attitudes toward animals and their relations to ethical ideologies, it is clear that a number of other variables remain unexplained, such as the frequency of meat eating and zoo (aquarium) visiting. In addition, due to the manner of information collection, this research suffered from a somewhat unbalanced distribution of participants (eg the number of urban respondents was much higher than that of rural respondents). This may explain why we did not find significant differences between rural and urban areas. Additionally, this limitation has also revealed the need to deploy face-to-face interviews in our follow-up research in order to reduce sampling errors.

Our results provided evidence that favourable attitudes toward animals were positively affected by ethical idealism, which is consistent with previous surveys reporting that public attitudes toward animals in the United States were positively associated with idealism (Galvin \& Herzog 1992; Nickell \& Herzog 1996). However, attitudes toward animals 
were negatively affected by ethical relativism in China, which is inconsistent with above surveys showing that ethical relativism was not related to attitudes toward animals in the United States (Galvin \& Herzog 1992; Nickell \& Herzog 1996). All these studies indicate that the same mechanisms underlying the effect of ethical idealism on attitudes toward animals might work in different countries to increase awareness on animal welfare. However, the mechanisms of how ethical relativism influences attitudes toward animals might differ between developed and developing countries.

\section{Animal welfare implications}

The present study highlights the significant positive relationship between ethical idealism and attitudes to animals, as well as the significant negative relationship between ethical relativism and attitudes to animals in China. This result implies that individuals who think their ethical behaviour will always lead to positive consequences and who believe in the existence of universal moral principles generally have high awareness of and positive attitudes toward animal welfare. Therefore, further consideration of how to balance and prioritise ethical idealism and relativism in order to improve people's positive attitudes toward animals is necessary. The findings of the correlation between ethical ideologies and attitudes toward animals can serve as a motivational platform on studies of how to increase Chinese people's awareness of animal welfare. Finally, as this is the first paper to look into the correlation between ethical ideologies and attitudes toward animals in China, further research concentrated on this correlation toward specific animals, such as companion animals, is needed to be designed, tested and refined for future work.

\section{Acknowledgements}

We acknowledge the effort of Flycatcher for their help with the data collection. We thank all the respondents for their participation in this survey. BS is funded by Chinese Scholarship Council (CSC) (Grant no 201406300005).

\section{References}

Banas JT and Parks JM 2002 Lambs among lions? The impact of ethical ideology on negotiation behaviors and outcomes. International Negotiation 7: 235-260. http://dx.doi.org/l0.II63 /|3823400276|38498|

Bègue L and Laine P-J 2016 Moral utilitarianism and attitudes toward animals. Ethics \& Behavior 26: I-6. http://dx.doi.org/ 10.1080/10508422.2016.1162720

Binngießer J, Wilhelm C and Randler C 2013 Attitudes toward animals among German children and adolescents. Anthrozoös 26: 325339. http://dx.doi.org//0.2752//753037/3XI3697429463475

Blakeley DN 2003 Listening to the animals: The Confucian view of animal welfare. Journal of Chinese Philosophy 30: 137-157. http://dx.doi.org/ I 0. I I I I/ I540-6253.00 I I I

Blazina C, Boyra G and Shen-Miller D 201 I The Psychology of the Human-Animal Bond. Springer: New York, USA. http:// dx.doi.org/I0.1007/978-I-44I9-976|-6
Cabin RJ and Mitchell RJ 2000 To Bonferroni or not to Bonferroni: when and how are the questions. Bulletin of the Ecological Society of America 81: 246-248. http://www.jstor.org/stable/20168454

Dalla Costa E, Guagliumi F, Cannas S, Minero $M$ and Palestrini C 2014 Can humans recognize emotional state in pet dogs by looking at their face? Journal of Veterinary Behavior: Clinical Applications and Research 9: e9. http://dx.doi.org/ 10.1016/j.jveb.2014.09.030

Davey G 2006 Chinese university students' attitudes toward the ethical treatment and welfare of animals. Journal of Applied Animal Welfare Science 9: 289-297. http://dx.doi.org//0.1207/ sI5327604jaws0904_4

Driscoll JW 1992 Attitudes toward animal use. Anthrozoös 5: 3239. http://dx.doi.org//0.2752/0892793927870 I I 575

Eagles PF and Muffitt S 1990 An analysis of children's attitudes toward animals. The Journal of Environmental Education 21: 4I-44. http://dx.doi.org// 0.1080/00958964.1990.10753747

Fidler M, Light P and Costall A 1996 Describing dog behavior psychologically: Pet owners versus non-owners. Anthrozoös 9: 196-200. http://dx.doi.org//0.2752/08927939678700 I356

Forsyth DR 1980 A taxonomy of ethical ideologies. Journal of Personality and Social Psychology 39: 175. http://dx.doi.org/I0.I 037/0022-35|4.39.1.175

Forsyth DR 1992 Judging the morality of business practices: The influence of personal moral philosophies. Journal of Business Ethics I I: 46 I-470. http://dx.doi.org// 0.1007/BF00870557

Forsyth DR and Pope WR 1984 Ethical ideology and judgments of social psychological research: Multidimensional analysis. Journal of Personality and Social psychology 46: 1365. http:// dx.doi.org/| 0. I037/0022-35 |4.46.6.1365

Galvin SL and Herzog HA 1992 Ethical ideology, animal rights activism, and attitudes toward the treatment of animals. Ethics \& Behavior 2: |4|-| 49. http://dx.doi.org/| 0.1207/s | 53270 |9eb0203_ I

Goldmeier J 1986 Pets or people: Another research note. The Gerontologist 26: 203-206. http://dx.doi.org//0.1093/geront/26.2.203

Hansson $\mathbf{H}$ and Lagerkvist C 2014 Defining and measuring farmers' attitudes to farm animal welfare. Animal Welfare 23: 4756. https://doi.org// 0.7/20/09627286.23.1.047

Herzog Jr HA, Betchart NS and Pittman RB 199| Gender, sex role orientation, and attitudes toward animals. Anthrozoös 4: |84-191. http://dx.doi.org//0.2752/08927939/787057| 70

Izmirli S and Phillips CJ 20 II The relationship between student consumption of animal products and attitudes to animals in Europe and Asia. British Food Journal 1/3: 436-450. http:/ /dx.doi.org/10.1 108/0007070 IIIIII6482

Kellert SR 1985a Attitudes toward animals: Age-related development among children. The Journal of Environmental Education 16: 29-39. http://dx.doi.org// 0.1080/00958964.1985.9942709

Kellert SR 1985b Public perceptions of predators, particularly the wolf and coyote. Biological conservation 31: 167-I89. http:// dx.doi.org//0.1016/0006-3207(85)90047-3

Kellert SR and Berry JK 1980 Knowledge, Affection and Basic Attitudes Toward Animals in American Society. Phase III. Government Printing Office: Washington DC, USA. http:// eric.ed.gov/?id=ED22924। 
Kellert SR and Berry JK 1987 Attitudes, knowledge, and behaviors toward wildlife as affected by gender. Wildlife Society Bulletin 15: 363-37I. http://www.jstor.org/stable/3782542

Kirk RE 201I International Encyclopedia of Statistical Science. Springer: Berlin Heidelberg, Germany. http://dx.doi.org//0.1007 1978-3-642-04898-2_518

Knight S, Nunkoosing K, Vrij A and Cherryman J 2003 Using grounded theory to examine people's attitudes toward how animals are used. Society \& Animals II: 307-327. http://dx.doi.org// 0.I I63/I56853003322796064

Knight S, Vrij A, Bard K and Brandon D 2009 Science versus human welfare? Understanding attitudes toward animal use. Journal of Social Issues 65: 463-483. http://dx.doi.org//0.116 3/I56853003322796064

Lee PC and Priston NE 2005 Human attitudes to primates: perceptions of pests, conflict and consequences for primate conservation. In: Paterson JD and Wallis J (eds) Commensalism and Conflict: The HumanPrimate Interface 4: I-23. Norman: American Society of Primatologists. http://citeseerx.ist.psu.edu/viewdoc/download?doi=10.1.I.46I.4509\&r ep=rep I \&t ype=pdf

Littlefair P 2006 Animals, Ethics and Trade. The Challenge of Animal Sentience. Earthscan: London, UK

Martens P, Enders MJ and Walker J 2016 The emotional life of companion animals: Attachment and subjective claims by owners of cats and dogs. Anthrozoös 29: 73-88. http://dx.doi.org// 0.1080/08927936.2015.1075299

McDonald JH 2009 Handbook of Biological Statistics. Sparky House Publishing: Baltimore, MD, USA. http://biostathand book.com/HandbookBioStatSecond.pdf

McPhedran S 2009 A review of the evidence for associations between empathy, violence, and animal cruelty. Aggression and Violent Behavior 14: I-4. http://dx.doi.org/I0.10I 6/j.avb.2008.07.005

Meng J 2009 Origins of attitudes towards animals. PhD Thesis, School of Veterinary Science, University of Queensland, Australia Nickell D and Herzog HA 1996 Ethical ideology and moral persuasion: Personal moral philosophy, gender, and judgments of pro-and anti-animal research propaganda. Society \& Animals 4: 5364. http://dx.doi.org/ I 0. I I63/ I56853096X00043

Ormandy EH and Schuppli CA 2014 Public attitudes toward animal research: a review. Animals 4: 39I-408. http://dx.doi.org/ 10.3390/ani403039l

Paul E and Serpell A 1993 Childhood pet keeping and humane attitudes in young adulthood. Animal Welfare 2: 321-337
Phillips C, Izmirli S, Aldavood S, Alonso M, Choe B, Hanlon A, Handziska A, Illmann G, Keeling $L$ and Kennedy M 2012 Students' attitudes to animal welfare and rights in Europe and Asia. Animal Welfare 21: 87. http://dx.doi.org/ 10.7120/09627286.25.3.377

Prokop P and Tunnicliffe SD 2010 Effects of having pets at home on children's attitudes toward popular and unpopular animals. Anthrozoös 23: 21-35. http://dx.doi.org//0.2752//753037| $0 \times 12627079939107$

Sankey H 2015 Constructively engaging with relativism. Metascience 24: 265-269. http://dx.doi.org//0.1007/s II0I6-0149972-x

Serpell JA 2004 Factors influencing human attitudes to animals and their welfare. Animal Welfare 13: |45-I5 |

Sharkin BS and Knox D 2003 Pet loss: Issues and implications for the psychologist. Professional Psychology: Research and Practice 34: 4I4. http://dx.doi.org//0.1037/0735-7028.34.4.4I4

Signal TD and Taylor N 2006 Attitudes to animals: Demographics within a community sample. Society \& Animals 14: |47-I57. http://dx.doi.org//0.1 163//56853006776778743

Sivadas E, Bardi Kleiser S, Kellaris J and Dahlstrom R 2003 Moral philosophy, ethical evaluations, and sales manager hiring intentions. Journal of Personal Selling \& Sales Management 23: 7-21. http://www.tandfonline.com/doi/abs//0.1080/08853 I34.2003.10748984 Spooner J, Schuppli C and Fraser D 2012 Attitudes of Canadian beef producers toward animal welfare. Animal Welfare 21: 273-283. https://doi.org// 0.7I 20/09627286.21.2.273

Tillé Y 2006 Sampling Algorithms. Springer Series in Statistics: New York, USA. http://link.springer.com/chapter/I0.1007/0-38734240-0 4

Walker JK, McGrath N, Nilsson DL, Waran NK and Phillips CJ 2014 The role of gender in public perception of whether animals can experience grief and other emotions. Anthrozoös 27: 25I-266. https://doi.org//0.2752/1753037 |4X|390382748760|

Wrobel TA and Dye AL 2003 Grieving pet death: Normative, gender, and attachment issues. OMEGA-Journal of Death and Dying 47: 385-393. https://doi.org/10.2190/QYV5-LLJI-T043-U0F9

Wuensch KL and Poteat GM 1998 Evaluating the morality of animal research: Effects of ethical ideology, gender, and purpose. Journal of Social Behavior and Personality 13: 139- 150. http://hdl.handle.net/I0822/9/2204 